DOI 10.31489/2019No2/68-73

UDC 662.642 .2

\title{
IMPROVING FUEL PROPERTIES USING THE FGX-12 CRUSHING AND SCREENING COMPLEX
}

\author{
Shaimerdenova K.M., Shunkeyev T.A., Ospanova D.A. \\ E.A. Buketov Karaganda State University, Karaganda, Republic of Kazakhstan, gulzhan.0106@mail.ru
}

\begin{abstract}
The method of improving the quality of coal by using a combined dry enrichment machine was considered. The description of combined dry enrichment machine, intended to process the run-of-mine coal from the Sarykol deposit of the Maikubensky lignite basin, was given. A coal concentrate, middlings and other enrichment products which were received as a result of processing, are accumulated in the warehouse. The main aim of the enrichment machine is to improve the qualitative characteristics of brown coal and, first of all, is an increase of coal calorific value (heat of combustion) and a reduction in ash content. As a result of enrichment, the shelf life of coal increases from 3 to 6 months.
\end{abstract}

Keywords: coal processing, enrichment, increase of calorific value, brown coal.

\section{Introduction}

The competence of the Sarykol surface coal mine is 3.0 million tons of coal per year, and is provided by industrial reserves and by productivity, quantity and layout of mining equipment. But, as following from the current situation on the brown coal market of the Maikubensky lignite basin, the need for run-of-mine coal from the Sarykol deposit does not currently exceed 0.7-1.0 million tons of coal per year. Taking into account marketing research of the brown coal consumption market and the possible prospects for the energy complex development in the Republic of Kazakhstan, was proposed a variant of improving the consumer properties of coal by dry enrichment. The enrichment of the mined fuel makes it possible to improve the quality characteristics of the final product and, accordingly, expand market outlets within the country and also beyond its borders.

Studies and recommendations for the enrichment of coals in the Maikubensky lignite basin included traditional enrichment methods in heavy medium, as well as the wet enrichment method. But for enrichment in heavy medium, additional materials such as zinc chloride and bromoform are needed, as well as magnetite weighting agent, which undoubtedly entails additional financial costs for the purchase and delivery of the required raw materials. After enrichment of the first lot of coal, magnetite becomes off-specification. To extract magnetite for reuse, off-specification suspension is regenerated, which also leads to additional energy costs and loss of time. In case of the wet enrichment method, a large amount of water is required, as well as apolar reagents: kerosene, diesel fuel, oil refining intermediates, which are additional costs and are rest on the final cost of product. But since there are no ponds nearby, there is a shortage of industrial water at the surface coal mine. In addition, the increased sludge formation and high soak ability of Maikubensky coals make both methods absolutely not working in this particular case. In other words, if we compare all three methods of coal enrichment, then only dry enrichment can be called the most economical, compact and efficient method [1].

For these purposes, a combined dry enrichment machine of the type FGX-12 manufactured by the PRC was purchased. The modern layout and implementation of foreign equipment has significantly reduced energy consumption and harmful effects on the environment. The possibility of separation in the air makes the entire process as simple as possible. There is no need to build capital-intensive buildings; it is enough to complete the installation in the open air. In order not to 
raise the rock mass, the combined dry enrichment machine can be installed in surface coal mine [2].

\section{Technological scheme and basic equipment}

In crushing and screening complex the enrichment process is carried out due to a self-produced medium (fine particles of coal enriched). The accuracy of the enrichment process and the productivity of given separators is much higher than that of traditional dry enrichment separators.

Moreover, this method is characterized by:

- the simplicity of enrichment schemes, low capital costs;

- the lack of need for water and obtaining dry products;

- the low final cost of the processing process and low energy consumption.

Effective dust removal meets the requirements of environmental protection. There is high yield of marketable coals. No sludge compared to wet enrichment methods. Fine coal particles are collected by dust collecting devices. The operating practice shows reliable work, lack of easily damaged parts. The technological scheme of the crushing and screening complex (CSC) is shown in Fig. 1 [3].

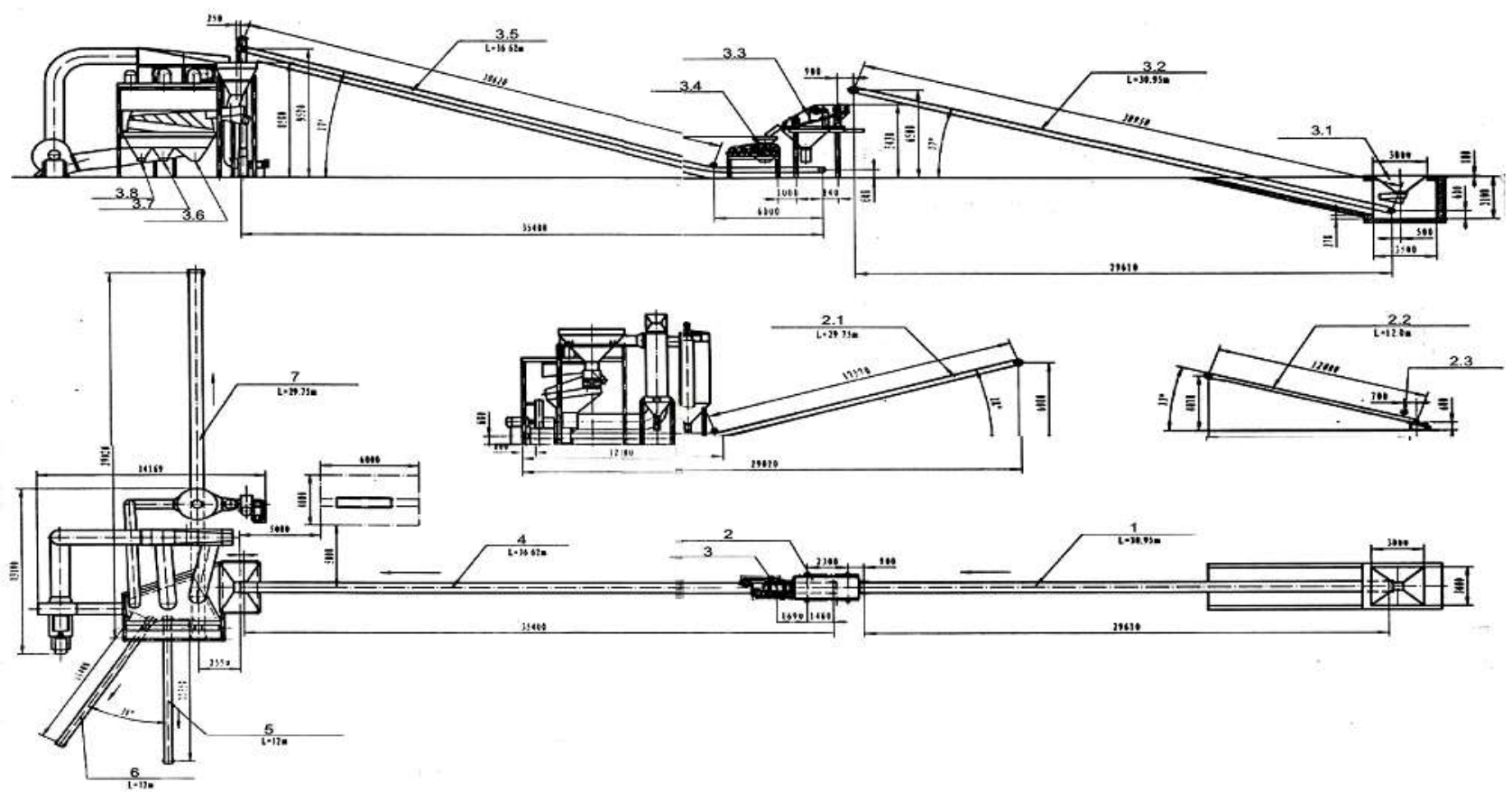

Fig.1. Crushing and screening complex (CSC):

1 - belt for screening $\amalg$ - 800 mm; 2 - screening SZD 1536 diameter - 80 mm; 3 - crusher 2PGF6550; 4 - belt for FGX Ш-800 mm; 5 - belt for middling Ш-500 mm; 6 - tape for solid Ш-500 mm;

7- tape for concentrate Ш-800 mm; 2.1- tape for concentrate Ш-800 mm; 2.2 - tape for solid (middling); 2.3-place of the fall of solid (middling); 3.1-receiving hopper and feeder; 3.2 - belt for screen Ш - $800 \mathrm{~mm} ; 3.3$ - screen SZD 1536 diameter - $80 \mathrm{~mm}$; 3.4 - crusher 2PGF6550; 3.5-belt for FGX Ш-800 mm; 3.6- concentrate yield; 3.7 - middling yield; 3.8-solid yield.

The combined dry enrichment machine includes the following component parts:

- combined dry enrichment machine FGX-12;

- a funnel of the coal receiving device with a feeder;

- belt conveyor of run-of-mine coal;

- vibrating grit;

- roll crusher;

- belt conveyor for feeding sorted coal to a combined dry enrichment machine; 
- belt conveyors for feeding enrichment products to accumulative warehouses;

- control cabin;

- control cabinet, cable products, bridge frame, fastenings.

The appearance of the combined dry enrichment machine of the type FGX-12 is shown in Fig.2 [4].

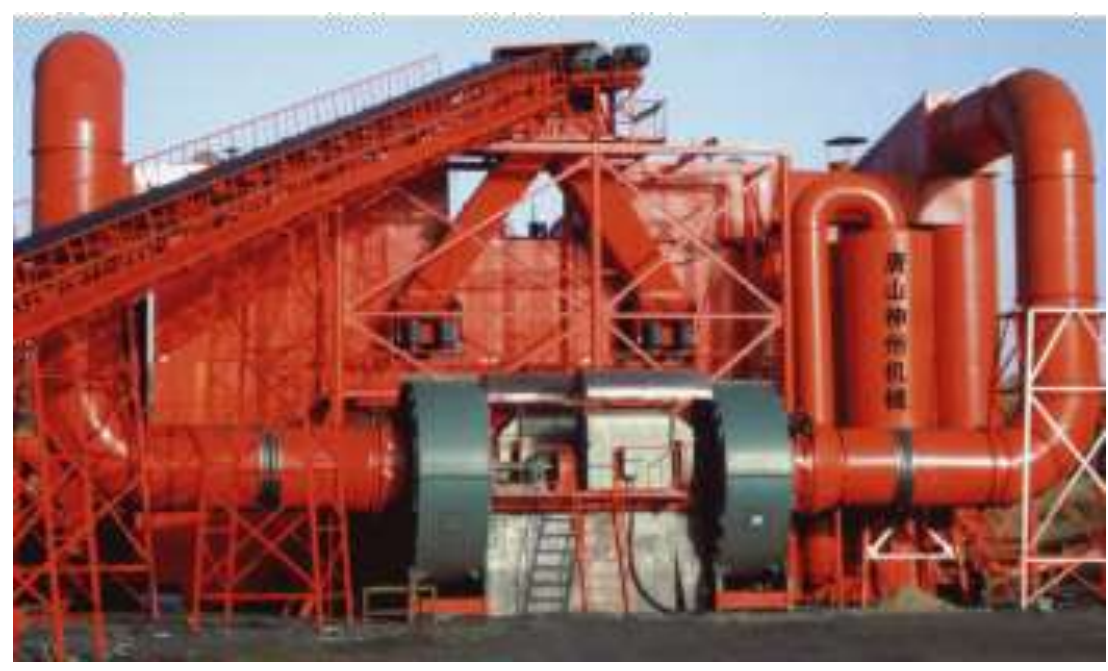

Fig.2. Combined dry enrichment machine of the type FGX-12 (main view)

Technical characteristics of the combined dry enrichment machine are shown in table 1.

Table 1. Technical characteristics of CDEM

\begin{tabular}{|l|l|}
\hline Model & FGX-12 \\
\hline Coarseness of coal enriched & $0-80 \mathrm{~mm}$ \\
\hline External humidity & $0-9 \%$ \\
\hline Performance & 120 per hour \\
\hline Coefficient of efficiency & More than $90 \%$ \\
\hline Total power & $410 \mathrm{kVt}$ \\
\hline Dimensions $(\mathrm{L} \times \mathrm{W} \times \mathrm{H})$ & $15.0 \times 13.0 \times 10.0 \mathrm{~m}$ \\
\hline
\end{tabular}

The processing and loading complex is a group of structures and installations, united by the technological process. The operation of the pneumatic concentration plant (separator of dry enrichment FGX-12) is based on the dry enrichment method. The performance of the concentration plant is $120 \mathrm{~m}^{3}$ / hour. The performance of the main fan is $24-30.4 \mathrm{~m}^{3} / \mathrm{s}$.

The outlet air pressure is $6.540-6.440 \mathrm{kPa}$. The separator has its own aspiration system, eliminating fugitive emissions of coal dust. For processing, coal from a receiving warehouse is supplied with a bulldozer or a loader to the horizontal part of the over loader. The over loader, lifting the coal to a height of $6.5 \mathrm{~m}$, feeds it for processing to screening. From under the screen (to prevent over milling and excessive utilization of the FGX-12 unit), fines of the 0-13 mm class are fed by a belt conveyor to the coal fines warehouse. Coal from the screen, class $13-300 \mathrm{~mm}$, is fed to the crusher and then, after crushing to class $50-60 \mathrm{~mm}$, by a belt conveyor into the receiving hopper of the FGX-12 dry concentration plant.

From the FGX-12 dry concentration plant, the products obtained are transported: concentrate delivered to the concentrate warehouse by a belt conveyor, warehouse formation, shipment by truck or excavator to dump trucks; middling - it is delivered to the middling warehouse by a belt 
conveyor, the formation of the warehouse, and shipment is carried out by a loader or excavator to dump trucks; solid - it is delivered to the solid warehouse by two belt conveyors, the formation of the warehouse, and shipment is carried out by a loader or excavator to dump trucks [5].

The technological scheme of processing run-of-mine coal on a combined dry enrichment machine includes the following operations:

- preliminary screening of small fractions $(0-80 \mathrm{~mm})$ on a vibrating grit;

- crushing of material with a particle size of $80-200 \mathrm{~mm}$ in a roll crusher;

- enrichment of run-of-mine coal.

Stationary belt conveyors with a belt width of $800 \mathrm{~mm}$ are used to transport material from the unit to the unit. Technological equipment is characterized by:

- increased productivity due to new construction solutions;

- high reliability and safety in operation.

The list and technical characteristics of the main technological equipment are given in Table 2 [6].

Table 2. Technical characteristics of the main technological equipment

\begin{tabular}{|c|c|c|c|}
\hline No & Name & Technical characteristic & Quantity \\
\hline 1. & Coal funnel with feeder & $\mathrm{V}=5 \mathrm{~m}^{3}$ & 1 \\
\hline 2. & Round vibrating grit & $\begin{array}{l}\text { The surface area is } 5.4 \mathrm{~m}^{2} \text {, the number of layers } \\
\text { is } 1 \text {, the vibration frequency is } 850 \text { times / min, } \\
\text { the amplitude of one vibration is } 3.5 \mathrm{~mm} \text {, and } \\
\text { the maximum size of the feedstock is } 200 \mathrm{~mm} \text {. }\end{array}$ & 1 \\
\hline 3. & Roll crusher & $\begin{array}{l}\text { The dimensions of the slugging rolls: diameter - } \\
650 \mathrm{~mm} \text {, length }-600 \mathrm{~mm} \text {, grain size of the } \\
\text { starting material }-80-200 \mathrm{~mm} \text {, grain size of the } \\
\text { product }-0-80 \mathrm{~mm} \text {, productivity }-80 \mathrm{t} / \mathrm{h} \text {. }\end{array}$ & 1 \\
\hline 4. & $\begin{array}{l}\text { Combined dry enrichment } \\
\text { machine FGX-12 }\end{array}$ & $\begin{array}{l}\text { The working surface area is } 12 \mathrm{~m}^{2} \text {, the size of } \\
\text { the enriched coal is } 0-80 \mathrm{~mm} \text {, the productivity } \\
\text { is } 80 \mathrm{t} / \mathrm{h} \text {, the enrichment efficiency is } 90 \% \text {. }\end{array}$ & 1 \\
\hline 5. & $\begin{array}{l}\text { Belt conveyor of run-of- } \\
\text { mine coal with supporting } \\
\text { structures, } \\
\text { ladders, loading and } \\
\text { unloading trays } \\
\end{array}$ & $\begin{array}{l}\text { Belt width }-800 \mathrm{~mm} \text {, conveyor length }-30.95 \\
\mathrm{~m} \text {, feed fineness - 0-200 mm, belt speed }-1.4 \mathrm{~m} \\
\text { / s, installation angle }-17 *\end{array}$ & 1 \\
\hline 6. & $\begin{array}{l}\text { Belt conveyor for feed to the } \\
\text { dry enrichment machine } \\
\text { with supporting structures, } \\
\text { platforms, ladders, loading } \\
\text { and unloading trays }\end{array}$ & $\begin{array}{l}\text { Belt width }-800 \mathrm{~mm} \text {, conveyor length }-36.62 \\
\mathrm{~m} \text {, feed fineness }-0-80 \mathrm{~mm} \text {, belt speed }-1.4 \mathrm{~m} / \\
\mathrm{s} \text {, installation angle }-17 *\end{array}$ & 1 \\
\hline 7. & $\begin{array}{l}\text { Belt conveyor of concentrate } \\
\text { with supporting structures, } \\
\text { platforms, ladders, loading } \\
\text { and unloading trays }\end{array}$ & $\begin{array}{l}\text { Belt width }-800 \mathrm{~mm} \text {, conveyor length }-29.75 \\
\mathrm{~m} \text {, feed fineness }-0-80 \mathrm{~mm} \text {, belt speed }-1.4 \mathrm{~m} / \\
\mathrm{s} \text {, installation angle }-17 *\end{array}$ & 1 \\
\hline 8. & $\begin{array}{l}\text { Belt conveyor of waste and } \\
\text { middlings with supporting } \\
\text { structures, platforms, } \\
\text { ladders, loading and } \\
\text { unloading trays }\end{array}$ & $\begin{array}{l}\text { Belt width }-500 \mathrm{~mm} \text {, conveyor length }-12.00 \\
\mathrm{~m} \text {, feed fineness }-0-80 \mathrm{~mm} \text {, belt speed }-1.4 \mathrm{~m} / \\
\mathrm{s} \text {, installation angle }-17 *\end{array}$ & 2 \\
\hline
\end{tabular}




\section{The principle of operation of the combined dry enrichment machine and the actual productivity of the equipment}

Run-of-mine coal of a fraction of 0-200 mm enters a coal receiving funnel with a feeder and at a certain speed starts moving up the conveyor belt towards the grit. Getting on a vibrating grit, coal of a fraction of $0-80 \mathrm{~mm}$ is immediately sifted and sent to enrichment on the next conveyor belt, and the remaining coal of a fraction of $80-200 \mathrm{~mm}$ goes to a roll crusher, where coal is crushed to a fraction of $0-80 \mathrm{~mm}$ and also, then sent for enrichment. Getting into the dry processing unit, coal is laid out on a vibrating grit, which is at a slope of 30 degrees. Compressors are installed under the grit. After the enriched coal got on grit, the process of enrichment of coal begins due to the action of a two-phase medium (from small particles in the initial coal and air) with a relatively higher specific gravity. Strong vibration and constant ascending air streams increase the looseness of the entire mass and exfoliate the material by density. Strong air currents lift small particles of dust up, which are then sent to the dust collector. Also, due to air flows, the process of exfoliation of the rock and clay from coal occurs, which leads to an improvement in coal performance.

The broken rock and clay, under the influence of vibration and air currents, begins to move up the vibrating grit and, moving along the unloading side, falls onto a conveyor belt intended for waste. Ultimately, on vibrating grit remains $0-80 \mathrm{~mm}$ fraction coal, purified from fine dust, rock and clay. Refined coal is enriched, as its quality characteristics are significantly improved [3-4]. The CDEM workflow is shown in Figure 3, [7].

In the period from 2016 to 2019, 509.76 thousand tons of run-of-mine coals were processed on a combined dry enrichment machine, of which 146.88 thousand tons of enriched coal and 362.88 thousand tons of middlings. A coal prepared for enrichment has the following basic characteristics: heat of combustion (calorific value) - $3500 \mathrm{kcal} / \mathrm{kg}$, ash content $-23.5 \%$, moisture $-19.5 \%$. Having passed all stages of dry enrichment, the product significantly improves its characteristics and already has the following parameters: heat of combustion (calorific value) - $4300 \mathrm{kcal} / \mathrm{kg}$, ash content $-19 \%$, moisture $-14.5 \%$.

A comparative analysis of the improving the quality of coal by using a combined dry enrichment machine results is shown in Figure 4, [8]. The $\mathrm{N}$ is a change of the coal indicators. The $\mathrm{N}$ value is calculated as the ratio of the initial basic characteristics indicators to finished products indicators.

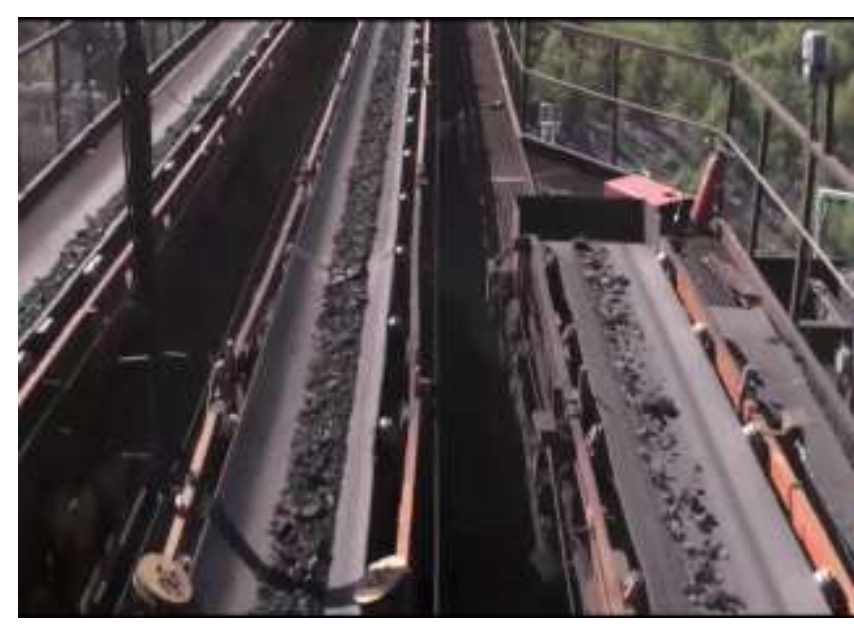

Fig.3. The CDEM workflow [7]

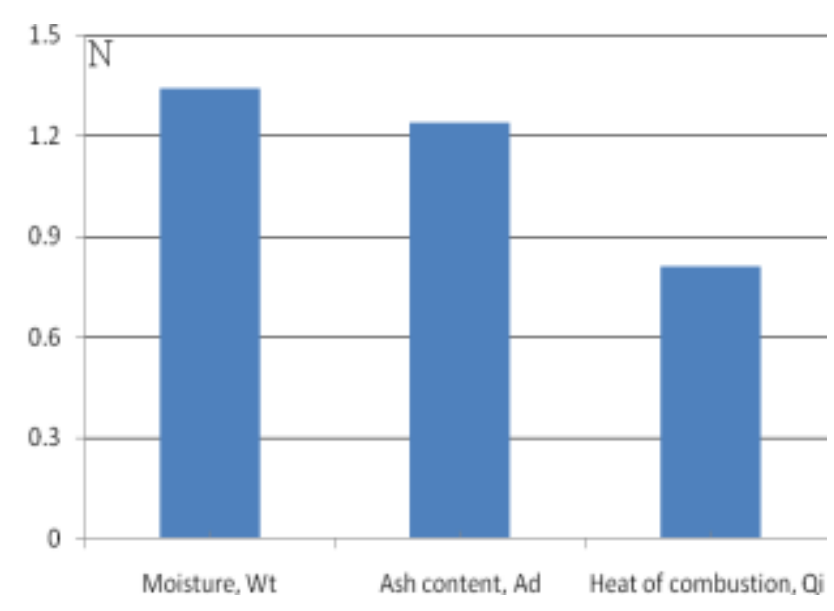

Fig.4. Comparative analysis of the results in the period from 2016 to 2019

Using this method, the moisture and ash content of coal decreased, as a result of which the heat of combustion of coal fuel from the Sarykol deposit increased. 


\section{Conclusion}

Thus, the combined dry enrichment machine of the type FGX-12 is the most effective when working with brown coals, since none of the other methods of coal enrichment showed such an improvement in the characteristics of coal.

Coal processing reduces ash content and significantly increases the power output of the station, reduces harmful emissions into the environment. The quality of the burned coal affects the power of the station, and the chemical composition of the ash affects the operational parameters of the furnace. The process of coal enrichment, which is based on the use of various physical forces, changes the characteristics of run-of-mine coal in the direction that most meets the requirements of the market.

There is a trend in the world when coal consumers for energy purposes tighten requirements for coal producers to reduce coal moisture, its ash content and lower sulfur content. So, there are Government programs to reduce the ash content of mined coal, which involves not only a significant increase in calorific value of fuel, but also allows to solve environmental problems associated with reducing emissions of pollutants into the environment by more than 2 times.

\section{REFERENCES}

1 Yong X. et al. FGX - 12 Installation and operating instructions for Sheng Zhou Engineering Plant. 2016, 213 p.

2 Rybtsov K.N., Dzyubenko A.L. Project for the construction and operation of a combined dry enrichment machine. LLP "Karagandagiproshakht and K". 2016, 217p. [in Russian]

3 Fuel enrichment technologies. Available at: www.iqtec.pro/ru/projects-2/thermal-electricstations/fuel-enrichment. 12/23/2019. [in Russian]

4 Usoltseva I. A., Peredery J. V., Krylenko R. I. Dry coal enrichment technology from the Korea Institute of Geo science and Mineral Resources (KIGAM). Available at: www.natd.gov.kz/wpcontent/uploads/2015/08/Obzor-1.pdf. [in Russian]

5 Pulyaev V. The equipment for enrichment of coal. Available at: www.china-bridge.ru/oborudovaniedlyaobogashheniya-uglya. 2/25/2019. [in Russian]

6 Technology of dry enrichment of coal from the company Osborn (South Africa). Electronic article. Available at: www.mining-media.ru/ru/article/obogach/684-tekhnologiy-sukhogo-obogashcheniya-uglya-otkompanii-osborn-yuar. 12/25/2019. [in Russian]

7 Stepanenko A.I. Dry enrichment - pneumatic separation complex "SEPAIR®". Available at: www.gmexp.ru/netcat_files/340/531/4cea1ac90c68d791b 7c8e24172892507. 12/25/2019. [in Russian]

8 Shunkeev T.A., Shaimerdenova K.M., Imanasova N.V., Ospanova D.A., Rakhmankyzy A. Improving the quality of coal by using a combined dry enrichment machine. Proceeding of the $11^{\text {th }}$ Intern. Scientific Conf. "Chaos and Structures in Nonlinear Systems. Theory and Experiment". Karaganda, 2019, pp. $311-314$.

Article accepted for publication 09.12.2019 